\title{
WEIGHTED INTEGRAL INEQUALITIES OF POINCARÉ TYPE
}

\author{
GEJUN BAO AND Yi LING
}

Abstract. In this paper, we give some weighted integral inequalities which generalize the wellknown Poincaré inequality. Our results can be used to generate other integral inequalities.

Mathematics subject classification (2000): 26D10, 26D15, $39 \mathrm{~B} 72$.

Key words and phrases: differential forms, A-harmonic tensors, Weighted integral inequalities.

\section{REFERENCES}

[1] C. O. HoRGAN, Integral bounds for solutions of nonlinear reaction-diffusion equations, Zeitschr. Angew. Math. Phys., 28, (1977), 197-204.

[2] C. O. HoRgAn, R. R. NACHLINGER, On the domain of attraction for steady states in heat condition, J. Engrg. Sci., 14, (1976), 143-148.

[3] C. O. Horgan, L. T. WHEELER, Spatial decay estimates for the Navier-Stokes equations with applocations to the problem of entry flow, SIAM J. Appl. Math., 35, (1978), 97-116.

[4] D. S. Mitrinović, Analytic Inequalities, Springer-Verlay, 1970.

[5] W. S. Cheung, On Poincaré type integral Inequalities, Proc. Amer. Math. Soc., 119, (1993), $857-863$.

[6] J. B. Garnett, Bounded Analytic Functions, Academic Press, New York, 1970.

[7] G. H. Hardy, J. E. Littlewood And G. Pólya, IneQualites, Cambridge University Press, Cambridge, 1952.

[8] S. DING, Integrability of conjugate A-harmonic tensors in $L^{S}(\mu)$-averaging domains, preprint.

[9] S. DING, New weighted integral inequalities for differential forms in some domains, Pacific J. Math., 194, (2000), 43-56. 